\title{
Autoimmunity and Immunotherapy in Narcolepsy
}

\author{
Min Jae Seong, $\mathrm{MD}^{1}$, Seung Bong Hong, MD, $\mathrm{PhD}^{2}$ \\ 'Department of Neurology, Samsung Medical Center, Sungkyunkwan University School of Medicine, Seoul, Korea \\ 2Department of Neurology, Samsung Medical Center, Sungkyunkwan University School of Medicine, Samsung Biomedical Research Institute, \\ Samsung Advanced Institute for Health Sciences \& Technology, Seoul, Korea
}

Narcolepsy is a neurological disorder characterized by excessive daytime sleepiness, cataplexy, hypnagogic hallucination, and sleep paralysis. Narcolepsy is caused by damage of hypocretin producing neurons in the lateral hypothalamus. The association of narcolepsy with HLA DQB1*0602 and high incidence following H1N1 pandemic in china, vaccination with pandemrix and an adjuvanted H1N1 vaccine suggests that pathophysiology of narcolepsy is involved in the immune system. This review focused on immunological associations and immunotherapy in narcolepsy.

Sleep Med Res 2017;8(1):1-7

Key Words Narcolepsy, Autoimmune, Immunoglobulin.

Received: June 20, 2017

Accepted: June 22, 2017

Correspondence

Seung Bong Hong, MD, PhD

Department of Neurology,

Samsung Medical Center,

Sungkyunkwan University

School of Medicine, Samsung Biomedical

Research Institute,

Samsung Advanced Institute

for Health Sciences \& Technology,

81 Irwon-ro, Gangnam-gu, Seoul 06351, Korea

Tel +82-2-3410-3599

Fax +82-2-3410-0052

E-mailssbhong@skku.edu

\section{INTRODUCTION}

Narcolepsy is a sleep disorder that affects approximately 0.02 percent to 0.05 percent of populations worldwide. ${ }^{1,2}$ Narcolepsy usually begins with abrupt excessive daytime sleepiness (EDS). Approximately 95 percent of cases of narcolepsy are sporadic, and occur in familial environments. Therefore, it has been suggested that susceptibility to environment is involved. ${ }^{3}$ Age of onset was varied from early childhood to age 50 by bi-modal distribution, with the main peak at age 15 and the secondary peak at age $36 .{ }^{4}$ The incidence is rare in patients older than 50 . The reason for the delay in diagnosis is that many clinicians do not know much about narcolepsy. Narcolepsy is often mistaken for depression or psychiatric illness. Symptoms are usually diagnosed 5-15 years after onset of symptoms, or after serious issues in daily life occur. ${ }^{5}$

Narcolepsy is characterized by decreased cerebrospinal fluid (CSF) hypocretin concentration associated with arousal, wakefulness and sleep regulation. ${ }^{6,7}$ Narcolepsy patients exhibit EDS, cataplexy (decreased muscle tone triggered by emotions) and abnormal transition to rapid eye movement (REM) sleep. ${ }^{8}$ Symptomatic fluctuations may appear in the clinical course and in general, EDS is the initial symptom and cataplexy occurs slowly over several months after onset and persists for life. ${ }^{9}$ Cataplexy may disappear spontaneously in some patients and it is presumed the patient adapts to his or her illness and avoids situations in which cataplexy can occur. Hypnagogic hallucinations or sleep paralysis are mostly transient. ${ }^{10-12}$ In many patients with narcolepsy, sleepiness is severe, resulting in difficulty focusing and staying awake at school, work and during periods of inactivity. ${ }^{13}$ Quality of life studies suggest the impact of narcolepsy is equal to Parkinson's disease. ${ }^{14}$

Hypocretin is synthesized in the lateral hypothalamus and is derived from a protein precursor called prepro-hypocretin. Prepro-hypocretin is enzymatically cleaved into two peptides, divided into hypocretin 1 and 2, and consists of 33 and 28 amino acids, respectively. There are two coned hypocretin receptors, HCRTR1 and HCRTR2, that are serpentine G-protein-coupled receptors. ${ }^{15}$ Hypocretin producing neuron is active during wakefulness and stimulates cortex, basal forebrain, brain stem and hypothalamus producing norepinephrine, serotonin, dopamine, and his- 
tamine. ${ }^{16-18}$ Hypocretin has a long-lasting effect on the target neuron, that helps to maintain daytime wakefulness, suppression of REM sleep, and therefore paralysis or dream-like hallucination, that is a REM sleep characteristic manifested during the day when it is deficient. The association between hypocretin and narcolepsy has been validated by the reduction of hypocretin peptide in CSF and hypothalamus in narcolepsy patients. ${ }^{7,9,19}$ Decreased hypocretin in CSF suggests that more than 90 percent of hypocretin producing neurons are lost, and this process has begun at narcolepsy onset. ${ }^{20}$ Hypocretin-producing cell damage is selective and the melanin-concentrating neuron is not impaired in narcolepsy patients. Specific deletion is a basis for the autoimmune process. ${ }^{19,21}$

Diagnosis can be made in definite clinical history but is limited, and polysomnography (PSG) and multiple sleep latency test (MSLT) are essential. PSG is needed to differentiate other sleep disorders such as obstructive sleep apnea syndrome that exhibit EDS, and MSLT is necessary to identify abnormal REM sleep transition during daytime naps. Narcolepsy was strongly suspected when MSLT revealed positive findings without other sleep disorders found in overnight PSG.

Main treatment strategy of narcolepsy is a symptomatic treatment. EDS is controled by wakefulness-promoting drugs such as modafinil or methylphenidate and these medications are associated with neurotransmitters of dopamine, serotonin and norepinephrine. ${ }^{22,23}$ Cataplexy is prevented by antidepressants (venlafaxine, floxetine, clomipramine and etc.) that inhibit re-uptake of norepinephrine and serotonin. In addition, sodium oxybate (sodium salt of gamma-hydroxybutyrate) that activates gammaaminobutyric acid type B receptor, is also used, but it is not known how this activation modulates sleepiness and cataplexy. ${ }^{24}$

However, these treatments are focused on the control of narcolepsy symptoms. Many researchers are conducting ongoing researches into treatment focusing on hypocretin depletion and hypocretin-producing neuron destruction.

Therefore, in this paper, we reviewed the autoimmune pathophysiology of narcolepsy and immunotherapy.

\section{THE IMMUNE SYSTEM AND NARCOLEPSY}

Researchers have focused on the significance of the potential role of the immune system in narcolepsy onset for many years. ${ }^{25-27}$ A study of the relationship between the immune system and narcolepsy began with the discovery of strong association between human leukocyte antigen (HLA) and narcolepsy. HLA encodes various subtypes of major histocompatibility complex (MHC) class I and II proteins, and MHC triggers immune response by $\mathrm{T}$ cell receptor (TCR) activation through presenting foreign peptide to T cells during infection. ${ }^{28} \mathrm{HLA}$ is associated with autoimmune diseases such as Graves' disease, rheumatoid arthritis and type 1 diabetes. ${ }^{29-32}$

HLA DQB1*0602 is found in 90 percent of patients with narcolepsy, and presence of this gene is known to increase the risk of narcolepsy by 200 times. $^{25,33}$ The pathogenic mechanism of DQB1*06:02 in narcolepsy is the destruction of hypocretin-producing neurons by interaction between specific TCR subtypes.

The autoimmune basis of narcolepsy, that was initiated by its association with HLA, has also revealed other mechanisms through research.

Second, there is a polymorphism of TCR alpha locus. ${ }^{34-36}$ TCR is expressed on the T cell surface and plays a key role in recognizing antigen by binding to HLA molecules on the surface of antigen presenting cells (APCs). ${ }^{37}$ Among them, alpha locus J region segment plays a crucial immunological role, and certain mutations of J region increase risk of developing narcolepsy. ${ }^{35}$

The third mechanism is bystander activation of autoreactive $\mathrm{T}$ cells. During viral infection, cytotoxic $\mathrm{T}$ cells are polyclonally stimulated. The cytokines secreted from antigen-responsive cells around the infected site directly stimulate surrounding T cells. ${ }^{31}$ In this pro-inflammatory micro-environment, normal $\mathrm{T}$ cells, not pathogen-specific $\mathrm{T}$ cells, are stimulated and therefore damage hypocretin cells. ${ }^{38}$

The fourth mechanism is molecular mimicry, that is characterized by structural similarity of pathogen and antigenic determinants of the host. ${ }^{37}$ This mechanism may occur at the cross reactive by helper T cells and MHC II/TCR synapse level. ${ }^{39}$ Activation of the cross-reactive $\mathrm{TH} 1$ of the microbial epitope and auto-antigen releases cytokines and chemokines and recruit activated monocytes and macrophages, leading to self-tissue damage. Subsequently, autoimmune disease persists from uptake by self-tissue antigen and APC. At MHC/TCR synapse level, this is caused by structural similarities between infectious agents (e.g., H1N1 and/ or Streptococcus pyogenes) and hypocretin neuron autoantigen. MHC class II binding groove selects peptide fragments with specific amino acids in the context of DQ1A*01:02-DQB1*06:02. The TCR recognizes the presented peptide with specific amino acid sequence and activates CD4 + T cells. However, the structure binding to $\mathrm{MHC}$ class II binding groove is similar to peptide fragments from infectious agents and hypocretin cell autoantigens, therefore the host binds and cross-reacts with CD4 + $\mathrm{T}$ cells instead of infectious agents, resulting in autoimmune response to hypocretin neurons. ${ }^{19,40}$

Clinical cases that support this are large-scale narcolepsy outbreaks after influenza infection or H1N1 influenza vaccination in China and Northern Europe. In China, after the pandemic H1N1 influenza in 2009, diagnosis of narcolepsy tripled but has since declined. Most patients were not vaccinated, and natural occurring influenza. An infection is associated with occurrence of narcolepsy. ${ }^{41}$ Therefore, onset of symptoms of narcolepsy usually begins in late spring and is presumed to occur in spring through bacterial (Streptococcus pyogenes) or viral infection during winter. ${ }^{41}$ The titer of antibody to antistreptolysin $\mathrm{O}$ is high immedi- 
ately after narcolepsy onset, that is the basis for the streptococcal infection to trigger the disease. ${ }^{42}$

In addition to influenza infection, vaccination also induces molecular mimicry. After the H1N1 vaccination of pandemic, AS03 (squalene, alpha-tocopherol) in Europe in 2009, narcolepsy occurred in considerable numbers of children and young adults in Finland. ${ }^{43}$ Finnish studies reported that narcolepsy diagnoses in children and young adults with $\mathrm{DQB} 1^{*} 06: 02$ for eight months after vaccination were 12.7-fold higher when compared to those not vaccinated. In Sweden, Finland, Ireland, and the U.K., the incidence has increased in most cases between the age 5 and 19, that is seen as a genetically susceptible person. ${ }^{43,44}$

Other HLA-DQ alleles, HLA-DP and HLA class I also affect genetic susceptibility. Gene polymorphisms such as TCRA, TCRB, P2RY11, EIF3G, ZNF365, IL10RB-IFNAR1, cathepsin H and TNFSF4 that influence immune function, are associated with autoimmunity of narcolepsy. ${ }^{28}$

However, evidence of autoimmunity is related to cellular immunity, and humoral immunity is lesser known. Hypocretin specific antibodies have been studied, but only negative or inconclusive results have been reported. ${ }^{27}$ Recent studies have reported increased total IgG and hypocretin-specific IgM in narcolepsy patients, but this finding was not specific in narcolepsy patients with low hypocretin levels. ${ }^{45,46}$

In summary, the association of HLA DQB1*06:02, TCR alpha locus polymorphism, Streptococcus pyogenes, or influenza A or $\mathrm{H} 1 \mathrm{~N} 1$ vaccination is a unique autoimmune feature of narcolepsy. ${ }^{28}$

\section{NARCOLEPSY TREATMENT OPTION BASED ON AUTOIMMUNITY}

Narcolepsy is treated with a combination of behavioral and pharmacologic approaches. ${ }^{47,48}$ Non-pharmacological treatment is cost efficient with no adverse effects. Non-pharmacological treatment is cirtical considering pharmacological treatment is more effective if combined with non-pharmacological treatment. Behavioral treatment for EDS is to improve quality of sleep at night and take a nap for 15-20 minutes in the afternoon, that reduces EDS. ${ }^{49}$

The goal of conventional treatment is to reduce EDS and cataplexy. Treatment of EDS maintains alertness through central nervous system stimulants such as dextroamphetamine, methylphenidate that act as a mechanism of dopamine re-uptake inhibition and release and modafinil that is a selective dopamine re-uptake blocker. In the case of mild to moderate daytime sleepiness, modafinil is a viable choice. Side effects and abuse are less. Methylphenidate, dextroamphetamine, and amphetamine analogues are more potent than modafinil and side effects are more common.

Cataplexy can improve through REM sleep suppression.
Norepinephrine and serotonin are related neurotransmitters for REM sleep suppression. Tricyclic antidepressants (TCA) include imipramine and clomipramine, and selective serotonin-reuptake inhibitors include venlafaxine and fluoxetine, that are more effective than TCA, acting more selectively on the serotonergic transporter than TCA.

Sodium oxybate has a mechanism to activate GABAB receptors and is effective in treating cataplexy and EDS. ${ }^{24}$

These treatments have focused on each symptom control, and many studies have been conducted in recent advanced treatment focusing on autoimmunity that causes hypocretin production, neuron damaging or reduction of hypocretin.

Hypocretin replacement/supplement treatment is theoretically a viable method and various approaches have been studied. The method of administering hypocretin-1 that is more stable than hypocretin-2 to blood and CSF has an issue in that it is difficult to pass the blood-brain barrier. Another method of administering hypocretin to the brain is intranasal administration. ${ }^{50}$ However, this is an animal-based experiment and human-based studies will be needed.

In addition, gene therapy/cell transplantation has been studied. Gene therapy via hypocretin genes overexpressing was effective in mice. ${ }^{51}$ To transplant hypocretin-producing cells, transplanting of hypothalamus of a neo-natal rat into brainstem of an adult rat was conducted. However, the issue of graft survival, like Parkinson's disease, must be solved. ${ }^{3}$

Immunomodulation treatment based on autoimmunity has also been studied. Steroid, immunoglobulin and plasmapheresis have been studied and immunoglobulin and plasmapheresis are effective. .2-57 $^{52}$

Studies on steroid therapy have been conducted on a dog and human. In dogs, frequency of cataplexy was reduced to 90 percent according to research, but some research reported that it was not effective. In the human study, an eight-year-old child was treated with prednisone, but it was ineffective. ${ }^{58-60}$

Plasmapheresis was administered in one patient and EDS and cataplexy improved, but recurred several weeks later. Symptoms improved after the second plasmapheresis and were successfully treated with sodium oxybate. ${ }^{52}$

The mechanism of autoimmune neurologic disorder of intravenous immunoglobulin has the following effects on auto-antibodies, 1) inhibition of complement binding and prevention of membranolytic attack complex formation, 2) modulation or blockade of Fc receptors on macrophages, 3) suppression of pathogenic cytokines and other immunoregulatory molecules. ${ }^{61}$ The effect of antibiotics is that IgG molecules in IVIg, that exhibit wide-range idiotypic and anti-idiotypic specificities, neutralize pathogenic auto-antibodies and prevent auto-antigen interaction. These mechanisms are targeted at pathogenesis associated with cellular and humoral immunity. In narcolepsy, a high dose of IVIg during the disease onset phase down-regulates $\mathrm{T}$ cell function, pathogenic cytokine and unidentified auto-antibody 


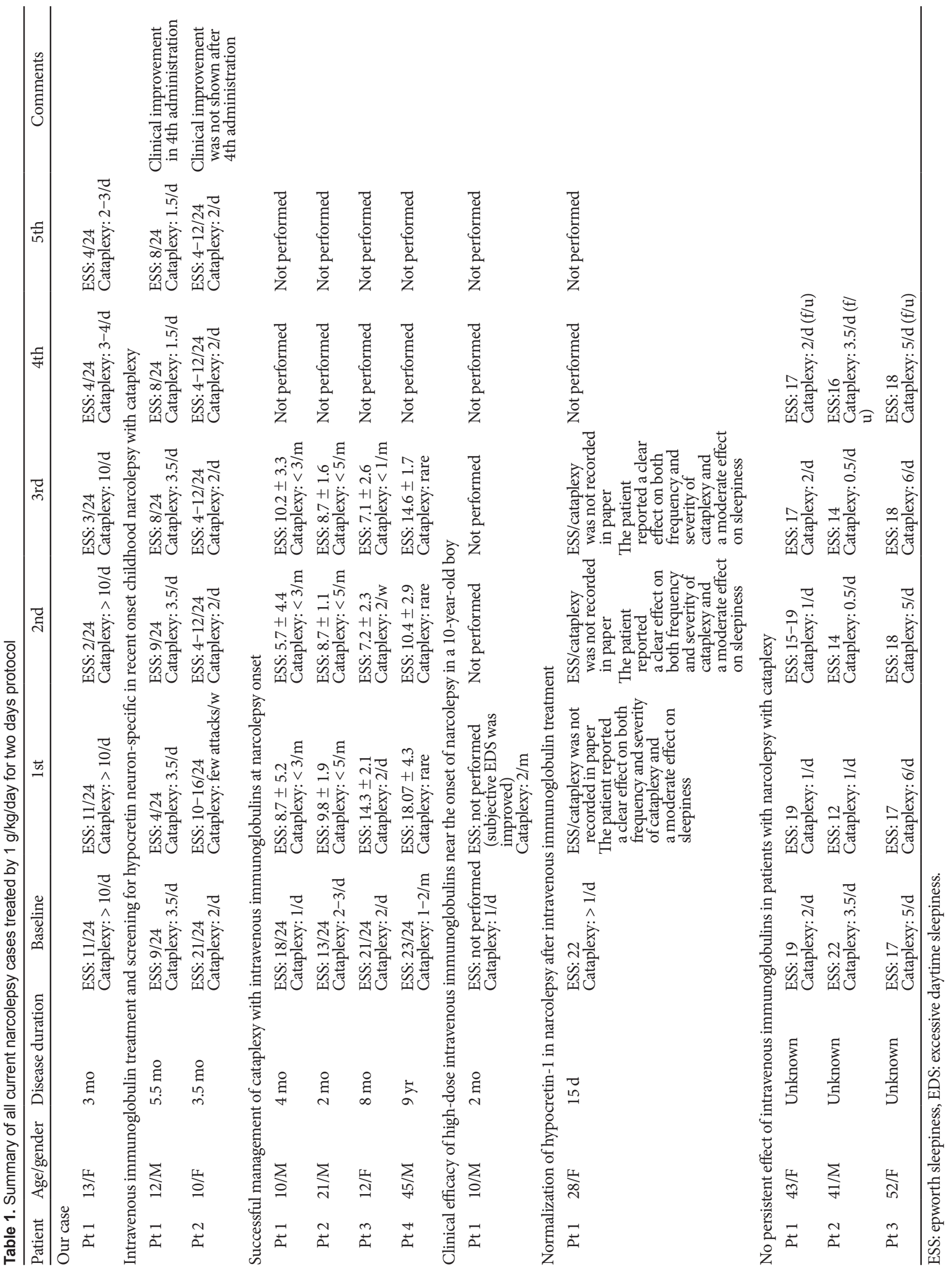


and interferes with auto-antigen recognition. ${ }^{54,61}$

Immunoglobulin is the most common immunomodulation study in narcolepsy treatment, but it is inadequate compared to immunoglobulin therapy for other diseases. This may be due to the low prevalence of narcolepsy and high cost of immunoglobulin.

Knudsen et al. ${ }^{55}$ reported a case of successful treatment of patients with recent onset childhood narcolepsy and cataplexy with IVIg and a table summarizing cases treated with IVIg for narcolepsy was presented. Knudsen was treated with $1 \mathrm{~g} / \mathrm{kg} /$ day for two days and five times at monthly intervals. However, the dose, duration, frequency, and additional medication of IVIg were variable for each patient in the table. Although IVIg is presumed to be effective, IVIg was not effective in some cases which is the reason for the lack of consensus in the protocol of IVIg treatment in narcolepsy.

Therefore, a systemic review of IVIg dose, treatment duration, and resposnes in narcolepsy patients is needed.

In 17 patients, the dose and treatment duration of IVIg were decided as $1 \mathrm{~g} / \mathrm{kg} /$ day for two days $\mathrm{s}^{53-56,62}$ or $0.4 \mathrm{~g} / \mathrm{kg} /$ day for five days. ${ }^{57,62}$ According to previous reports, a total of 11 patients were treated with IVIg $1 \mathrm{~g} / \mathrm{kg} /$ day for two days protocol (Table 1). The disease duration of the patients at the time of IVIg administration ranged from 15 days to 9 years. There were six males and five females. Ages ranged from 10-52 years old. Each patient received IVIg 1, 3 or 5 times. One patient received IVIg one time, and then took oral prednisolone for six weeks in addition to IVIg administration. A total of eight patients received IVIg three times, and one of them was treated with prednisolone too. Two patients received only prednisolone therapy five times.

One out of 11 patients was 52 years old and disease duration was not mentioned. IVIg was administered three times, but clinical improvement was not revealed. Ten patients had temporary or sustained improvement in symptoms (10/11, 90.9 percent). In symptomatic improvement, according to the number of administration, eight patients improved after the first administration, one patient had improved symptoms after the second administration, no patient improved in the third administration and one patient improved in the fourth administration. Six patients had sustained clinical improvement during follow up periods $(6 / 10$, 60 percent) and there were five patients with disease duration within six months and one patient was nine years $(12 / \mathrm{m}, 10 / \mathrm{m}$, $21 / \mathrm{m}, 12 / \mathrm{f}, 45 / \mathrm{m}, 10 / \mathrm{m})$. Four of the six patients improved symptoms after the first administration (4/6, 66.6 percent) and each patient had improved symptoms after the second and fourth administrations. Follow-up test for MSLT or maintenance of wakefulness test (MWT) was conducted in nine patients. Three patients underwent MSLT, two patients underwent MWT and five patients underwent MSLT and MWT. In patients that performed only MSLT, one patient revealed improvement (1/3, 33 percent). Two patients that underwent MWT revealed improvement of MWT findings. None of the patients that under- went MSLT and MWT improved the outcome. There was no correlation between clinical parameters and sleep parameters in evaluation of treatment efficacy and this was known in past reports..$^{57,63}$

The efficacy of IVIg treatment is related to disease duration and onset age ${ }^{54,55,57}$ Shorter disease duration and younger age make for better efficacy but there is no definite criterion for disease duration and onset age, and depending on literature, effects of treatment, timing and age, on effectiveness are inconsistent. Effect of treatment time on efficacy is based on the hypothesis that the shorter the disease duration, the lower the destruction of hypocretin-producing neurons by autoimmune. There is no evidence for normalization of hypocretin after IVIg treatment, but in patients with narcolepsy, CSF hypocretin level is generally low, suggesting that more than 90 percent of hypocretin-producing neurons are damaged. ${ }^{7,40,64,65}$ Patients with hypocretin levels in complete deficiency state did not have a positive effect with IVIg treatment, and hypocretin levels in early-treatment patients were higher than those in later course patients. ${ }^{55,56}$ Therefore, if hypocretin neuron is not completely destructive at time of treatment, the autoimmune process is reversible with IVIg treatment.

Serious side effects were not specifically reported in the previous case. Commonly known side effects of IVIg include thromboembolic events, migraine, aseptic meningitis, urticarial, pruritus, anaphylactic reaction, and renal tubular necrosis, but side effects reported in the case were infrequent flushes and headaches.

\section{CONCLUSION}

The association of narcolepsy with HLA, TCR polymorphism, and large-scale development after influenza support autoimmune. TCR polymorphism and vaccination are unique autoimmune features of narcolepsy. Narcolepsy caused by this mechanism triggers severe daily disability due to EDS and cataplexy. However, most treatments administered in many clinics remain as symptomatic treatment rather than treatment by approach of pathophysiology. Use of long-term stimulants also have side effects.

Therefore, treatment based on underlying disease pathology and therefore a deeper understanding of the pathophysiology of narcolepsy is needed. Until now, cellular immunity had been clarified, but humoral immunity and antibody are unknown, therefore research is also needed on these subjects.

Although there are a limited number of cases treated by IVIg in narcolepsy, there have been reports of apparent clinical improvement in IVIg treatment. Guidelines and/or protocols including indication, dose and treatment duration should be established by research in fundamental treatment based on autoimmunity. 


\section{Acknowledgments}

This research was supported by a grant of the Korea Health Technology R\&D Project through the Korea Health Industry Development Institute (KHIDI), funded by the Ministry of Health \& Welfare, Republic of Korea (grant number: HI16C1643).

\section{Conflicts of Interest}

The authors have no financial conflicts of interest.

\section{REFERENCES}

1. Hublin C, Kaprio J, Partinen M, Koskenvuo M, Heikkila K, Koskimies $\mathrm{S}$, et al. The prevalence of narcolepsy: an epidemiological study of the Finnish Twin Cohort. Ann Neurol 1994;35:709-16.

2. Ohayon MM, Priest RG, Zulley J, Smirne S, Paiva T. Prevalence of narcolepsy symptomatology and diagnosis in the European general population. Neurology 2002;58:1826-33.

3. Thorpy M. Therapeutic advances in narcolepsy. Sleep Med 2007;8:42740.

4. Dauvilliers Y, Montplaisir J, Molinari N, Carlander B, Ondze B, Besset A, et al. Age at onset of narcolepsy in two large populations of patients in France and Quebec. Neurology 2001;57:2029-33.

5. Thorpy MJ, Krieger AC. Delayed diagnosis of narcolepsy: characterization and impact. Sleep Med 2014;15:502-7.

6. Gerashchenko D, Murillo-Rodriguez E, Lin L, Xu M, Hallett L, Nishino $\mathrm{S}$, et al. Relationship between CSF hypocretin levels and hypocretin neuronal loss. Exp Neurol 2003;184:1010-6.

7. Thannickal TC, Moore RY, Nienhuis R, Ramanathan L, Gulyani S, Aldrich $\mathrm{M}$, et al. Reduced number of hypocretin neurons in human narcolepsy. Neuron 2000;27:469-74.

8. American Academy of Sleep Medicine. International Classification of Sleep Disorders: Diagnostic and Coding Manual. 2nd ed. Westchester, IL: American Academy of Sleep Medicine 2005.

9. Burgess CR, Scammell TE. Narcolepsy: neural mechanisms of sleepiness and cataplexy. J Neurosci 2012;32:12305-11.

10. Billiard M. Narcolepsy: current treatment options and future approaches. Neuropsychiatr Dis Treat 2008;4:557-66.

11. Broughton WA, Broughton RJ. Psychosocial impact of narcolepsy. Sleep 1994;17(8 Suppl):S45-9.

12. Vignatelli L, D’Alessandro R, Mosconi P, Ferini-Strambi L, Guidolin L, De Vincentiis A, et al. Health-related quality of life in Italian patients with narcolepsy: the SF-36 health survey. Sleep Med 2004;5:467-75.

13. Scammell TE. Narcolepsy. N Engl J Med 2015;373:2654-62.

14. Beusterien KM, Rogers AE, Walsleben JA, Emsellem HA, Reblando JA, Wang L, et al. Health-related quality of life effects of modafinil for treatment of narcolepsy. Sleep 1999;22:757-65.

15. Sakurai T, Amemiya A, Ishii M, Matsuzaki I, Chemelli RM, Tanaka H, et al. Orexins and orexin receptors: a family of hypothalamic neuropeptides and $\mathrm{G}$ protein-coupled receptors that regulate feeding behavior. Cell 1998;92:1 page following 696.

16. Blouin AM, Fried I, Wilson CL, Staba RJ, Behnke EJ, Lam HA, et al. Human hypocretin and melanin-concentrating hormone levels are linked to emotion and social interaction. Nat Commun 2013;4:1547.

17. Estabrooke IV, McCarthy MT, Ko E, Chou TC, Chemelli RM, Yanagisawa $\mathrm{M}$, et al. Fos expression in orexin neurons varies with behavioral state. J Neurosci 2001;21:1656-62.

18. Lee MG, Hassani OK, Jones BE. Discharge of identified orexin/hypocretin neurons across the sleep-waking cycle. J Neurosci 2005;25:671620.

19. Peyron C, Faraco J, Rogers W, Ripley B, Overeem S, Charnay Y, et al. A mutation in a case of early onset narcolepsy and a generalized absence of hypocretin peptides in human narcoleptic brains. Nat Med 2000;6: 991-7.

20. Savvidou A, Knudsen S, Olsson-Engman M, Gammeltoft S, Jennum P, Palm L. Hypocretin deficiency develops during onset of human narco- lepsy with cataplexy. Sleep 2013;36:147-8.

21. Andlauer O, Moore H 4th, Hong SC, Dauvilliers Y, Kanbayashi T, Nishino S, et al. Predictors of hypocretin (orexin) deficiency in narcolepsy without cataplexy. Sleep 2012;35:1247-55F.

22. Randomized trial of modafinil for the treatment of pathological somnolence in narcolepsy. US Modafinil in Narcolepsy Multicenter Study Group. Ann Neurol 1998;43:88-97.

23. Robertson SD, Matthies HJ, Galli A. A closer look at amphetamine-induced reverse transport and trafficking of the dopamine and norepinephrine transporters. Mol Neurobiol 2009;39:73-80.

24. Vienne J, Bettler B, Franken P, Tafti M. Differential effects of GABAB receptor subtypes, \{gamma\}-hydroxybutyric acid, and baclofen on EEG activity and sleep regulation. J Neurosci 2010;30:14194-204.

25. Mignot E, Lin X, Hesla PE, Dement WC, Guilleminault C, Grumet FC. A novel HLA DR17, DQ1 (DQA1-0102/DQB1-0602 positive) haplotype predisposing to narcolepsy in Caucasians. Sleep 1993;16:764-5.

26. Mignot E, Tafti M, Dement WC, Grumet FC. Narcolepsy and immunity. Adv Neuroimmunol 1995;5:23-37.

27. Overeem S, Black JL 3rd, Lammers GJ. Narcolepsy: immunological aspects. Sleep Med Rev 2008;12:95-107.

28. Mahlios J, De la Herrán-Arita AK, Mignot E. The autoimmune basis of narcolepsy. Curr Opin Neurobiol 2013;23:767-73.

29. Dorman JS, Bunker CH. HLA-DQ locus of the human leukocyte antigen complex and type 1 diabetes mellitus: a HuGE review. Epidemiol Rev 2000;22:218-27.

30. Newton JL, Harney SM, Wordsworth BP, Brown MA. A review of the MHC genetics of rheumatoid arthritis. Genes Immun 2004;5:151-7.

31. Singal DP, Blajchman MA. Histocompatibility (HL-A) antigens, lymphocytotoxic antibodies and tissue antibodies in patients with diabetes mellitus. Diabetes 1973;22:429-32.

32. van der Horst-Bruinsma IE, Visser H, Hazes JM, Breedveld FC, Verduyn W, Schreuder GM, et al. HLA-DQ-associated predisposition to and dominant HLA-DR-associated protection against rheumatoid arthritis. Hum Immunol 1999;60:152-8.

33. Mignot E, Lin X, Arrigoni J, Macaubas C, Olive F, Hallmayer J, et al. DQB1*0602 and DQA1*0102 (DQ1) are better markers than DR2 for narcolepsy in Caucasian and black Americans. Sleep 1994;17(8 Suppl): S60-7.

34. Bernardini C, Lattanzi W, Bosco P, Franceschini C, Plazzi G, Michetti $\mathrm{F}$, et al. Genome-wide gene expression profiling of human narcolepsy. Gene Expr 2012;15:171-81.

35. Hallmayer J, Faraco J, Lin L, Hesselson S, Winkelmann J, Kawashima $\mathrm{M}$, et al. Narcolepsy is strongly associated with the T-cell receptor alpha locus. Nat Genet 2009;41:708-11.

36. Han F, Lin L, Li J, Aran A, Dong SX, An P, et al. TCRA, P2RY11, and CPT1B/CHKB associations in Chinese narcolepsy. Sleep Med 2012;13: 269-72.

37. Petrie HT, Livak F, Burtrum D, Mazel S. T cell receptor gene recombination patterns and mechanisms: cell death, rescue, and T cell production. J Exp Med 1995;182:121-7.

38. Fontana A, Gast H, Reith W, Recher M, Birchler T, Bassetti CL. Narcolepsy: autoimmunity, effector $\mathrm{T}$ cell activation due to infection, or $\mathrm{T}$ cell independent, major histocompatibility complex class II induced neuronal loss? Brain 2010;133(Pt 5):1300-11.

39. De la Herrán-Arita AK, García-García F. Narcolepsy as an immunemediated disease. Sleep Disord 2014;2014:792687.

40. Sfriso P, Ghirardello A, Botsios C, Tonon M, Zen M, Bassi N, et al. Infections and autoimmunity: the multifaceted relationship. J Leukoc Biol 2010;87:385-95.

41. Han F, Lin L, Warby SC, Faraco J, Li J, Dong SX, et al. Narcolepsy onset is seasonal and increased following the $2009 \mathrm{H} 1 \mathrm{~N} 1$ pandemic in China. Ann Neurol 2011;70:410-7.

42. Aran A, Lin L, Nevsimalova S, Plazzi G, Hong SC, Weiner K, et al. Elevated anti-streptococcal antibodies in patients with recent narcolepsy onset. Sleep 2009;32:979-83. 
43. Nohynek H, Jokinen J, Partinen M, Vaarala O, Kirjavainen T, Sundman J, et al. AS03 adjuvanted AH1N1 vaccine associated with an abrupt increase in the incidence of childhood narcolepsy in Finland. PLoS One 2012;7:e33536.

44. Partinen M, Saarenpää-Heikkilä O, Ilveskoski I, Hublin C, Linna M, Olsén P, et al. Increased incidence and clinical picture of childhood narcolepsy following the $2009 \mathrm{H} 1 \mathrm{~N} 1$ pandemic vaccination campaign in Finland. PLoS One 2012;7:e33723.

45. Deloumeau A, Bayard S, Coquerel Q, Déchelotte P, Bole-Feysot C, Carlander B, et al. Increased immune complexes of hypocretin autoantibodies in narcolepsy. PLoS One 2010;5:e13320.

46. Tanaka S, Honda M. IgG abnormality in narcolepsy and idiopathic hypersomnia. PLoS One 2010;5:e9555.

47. Lecendreux M. Pharmacological management of narcolepsy and cataplexy in pediatric patients. Paediatr Drugs 2014;16:363-72.

48. Mignot EJ. A practical guide to the therapy of narcolepsy and hypersomnia syndromes. Neurotherapeutics 2012;9:739-52.

49. Morgenthaler TI, Kapur VK, Brown T, Swick TJ, Alessi C, Aurora RN, et al. Practice parameters for the treatment of narcolepsy and other hypersomnias of central origin. Sleep 2007;30:1705-11.

50. Hanson LR, Frey WH 2nd. Intranasal delivery bypasses the bloodbrain barrier to target therapeutic agents to the central nervous system and treat neurodegenerative disease. BMC Neurosci 2008;9 Suppl 3:S5.

51. Mieda M, Willie JT, Hara J, Sinton CM, Sakurai T, Yanagisawa M. Orexin peptides prevent cataplexy and improve wakefulness in an orexin neuron-ablated model of narcolepsy in mice. Proc Natl Acad Sci U S A 2004;101:4649-54.

52. Chen W, Black J, Call P, Mignot E. Late-onset narcolepsy presenting as rapidly progressing muscle weakness: response to plasmapheresis. Ann Neurol 2005;58:489-90.

53. Dauvilliers Y, Abril B, Mas E, Michel F, Tafti M. Normalization of hypocretin-1 in narcolepsy after intravenous immunoglobulin treatment. Neurology 2009;73:1333-4.

54. Dauvilliers Y, Carlander B, Rivier F, Touchon J, Tafti M. Successful management of cataplexy with intravenous immunoglobulins at narcolepsy onset. Ann Neurol 2004;56:905-8.
55. Knudsen S, Mikkelsen JD, Bang B, Gammeltoft S, Jennum PJ. Intravenous immunoglobulin treatment and screening for hypocretin neuron-specific autoantibodies in recent onset childhood narcolepsy with cataplexy. Neuropediatrics 2010;41:217-22.

56. Lecendreux M, Maret S, Bassetti C, Mouren MC, Tafti M. Clinical efficacy of high-dose intravenous immunoglobulins near the onset of narcolepsy in a 10-year-old boy. J Sleep Res 2003;12:347-8.

57. Plazzi G, Poli F, Franceschini C, Parmeggiani A, Pirazzoli P, Bernardi F, et al. Intravenous high-dose immunoglobulin treatment in recent onset childhood narcolepsy with cataplexy. J Neurol 2008;255:1549-54.

58. Boehmer LN, Wu MF, John J, Siegel JM. Treatment with immunosuppressive and anti-inflammatory agents delays onset of canine genetic narcolepsy and reduces symptom severity. Exp Neurol 2004;188:292-9.

59. Hecht M, Lin L, Kushida CA, Umetsu DT, Taheri S, Einen M, et al. Report of a case of immunosuppression with prednisone in an 8-yearold boy with an acute onset of hypocretin-deficiency narcolepsy. Sleep 2003;26:809-10.

60. Schatzberg SJ, Cutter-Schatzberg K, Nydam D, Barrett J, Penn R, Flanders J, et al. The effect of hypocretin replacement therapy in a 3-yearold Weimaraner with narcolepsy. J Vet Intern Med 2004;18:586-8.

61. Dalakas MC. Intravenous immunoglobulin in autoimmune neuromuscular diseases. JAMA 2004;291:2367-75.

62. Valko PO, Khatami R, Baumann CR, Bassetti CL. No persistent effect of intravenous immunoglobulins in patients with narcolepsy with cataplexy. J Neurol 2008;255:1900-3.

63. Littner MR, Kushida C, Wise M, Davila DG, Morgenthaler T, Lee-Chiong T, et al. Practice parameters for clinical use of the multiple sleep latency test and the maintenance of wakefulness test. Sleep 2005;28:11321.

64. Mignot E, Lammers GJ, Ripley B, Okun M, Nevsimalova S, Overeem S, et al. The role of cerebrospinal fluid hypocretin measurement in the diagnosis of narcolepsy and other hypersomnias. Arch Neurol 2002;59: 1553-62.

65. Nishino S, Ripley B, Overeem S, Lammers GJ, Mignot E. Hypocretin (orexin) deficiency in human narcolepsy. Lancet 2000;355:39-40. 